\title{
Effects of Sleep Patterns on the Subjective Health Status in Older Men from the 7th Korea National Health and Nutrition Examination Survey, 2016
}

\author{
Hye Rim Hwang, Yun-Jin Kim \\ Department of Family Medicine, Pusan National University Hospital, Pusan National University School of Medicine, Pusan, Korea
}

\author{
Corresponding Author: \\ Yun-Jin Kim, MD \\ Department of Family Medicine, Pusan \\ National University Hospital, Pusan \\ National University School of \\ Medicine, 179 Gudeok-ro, Seo-gu, \\ Busan 49241, Korea \\ E-mail: yujkim@pusan.ac.kr \\ ORCID: \\ https://orcid.org/0000-0002-0204-3253
}

Received: March 2, 2020

Revised: April 30, 2020

Accepted: May 23, 2020

\begin{abstract}
Background: Sleeping is a major component of health. The prevalence of sleep disorders is expected to be high in older adults, and sleep habits generally differ on weekdays and weekends. This study aimed to clarify the associations between sleep habits and the subjective health status of older adults. Methods: This study analyzed data of 1,678 older adults (695 men and 883 women) aged 65 years or older who had participated in the 2016 Korea National Health and Nutrition Examination Survey (KNHANES VII-1) conducted by the Korea Centers for Disease Control and Prevention. The participants' subjective health perceptions were analyzed according to their sleep habits. Results: Weekday and weekend sleep durations were related to subjective health in older men $(p<0.05)$ but not in women. The subjective health perception was significantly better for a 9-hour sleep duration than for a 7-hour sleep duration in older men. Sleeping and waking times on weekdays and weekends were not related to the subjective health of either men or women. Conclusion: Weekday and weekend sleep durations were related to subjective health perception in older men.
\end{abstract}

Key Words: Sleep, Health status, Elderly

\section{Introduction}

Sleeping is a major component of health, and sleep disorders increase the risk of major diseases, including cardiovascular disease. ${ }^{1)}$ A previous study reported associations between sleep disorder and heart failure, coronary heart disease, and irritable bowel syndrome. ${ }^{2)}$ Sleep problems are well known to affect the quality of life, ${ }^{3)}$ including poor response to health that indicates a decrease in subjective health perception. Furthermore, sleep disorders, including insomnia, daytime sleepiness, ${ }^{4)}$ short sleep duration, and long sleep duration, ${ }^{5)}$ are associated with decreases in subjective health perception. Sleep quality is also associated with decreased quality of life, including subjective health perception. ${ }^{6)}$

Subjective health perception involves recognizing one's health status; this information can then be used to assess an individual's general health status. ${ }^{7}$ In addition, regardless of the actual state of health, if the subjective health perception is poor, the level of daily activity is low, which could negatively affect the state of wellbeing. ${ }^{8)}$

In contrast, it is well-known that sleep patterns change with age, ${ }^{1)}$ that aging is a major cause of sleep disorders, and that various factors are related to sleep disorders in older adults. ${ }^{9)}$ They have decreased deep sleep, difficulty falling asleep, increased arousal while sleeping, and decreased total sleeping duration. ${ }^{10)}$ These observations suggest a high prevalence of sleep disorders in older adults. ${ }^{11)}$ Thus, these individuals with a high prevalence of sleep problems may also have a high possibility of reduced subjective health perception, which may ultimately affect the actual health status.

This study assessed the relationship between sleep habits and subjective health perception rather than the quality of sleep and sleep disorders, which have been evaluated in previous studies. Sleep habits generally differ between weekdays and weekends. In most cases, weekend sleep duration is relatively longer, as reported by the Korean National Health and Nutrition Examination Survey 
(KNHANES), ${ }^{12)}$ and may do so even after retirement. Moreover, as older adults are more likely to live according to traditional gender roles, sleep habits may also differ according to sex. Thus, the purpose of this study was to clarify the association between sleep habits and subjective health status in older adults.

\section{Materials and Methods}

\section{Participants}

This study analyzed data of 1,678 older people (695 men and 883 women) aged 65 years or older who participated in the 2016 Korea National Health and Nutrition Examination Survey (KNHANES VII-1) conducted by the Korea Centers for Disease Control and Prevention. ${ }^{13)}$

From the KNHANES, the extraction frame was stratified based on cities, provinces, municipalities, and housing types (general houses, apartments, newly built apartments). This study was conducted from January to December 2016 for all households with person over one year old or older from among 4,416 households nationwide. Because the KNHANES datasets do not include identifiable personal information, all studies using these data are excluded from the requirement for institutional review board approval.

\section{Data Collection and Variables}

We analyzed data on the participants' age, spouse cohabitation, household income, weekday and weekend sleeping times, weekday and weekend waking times, number of days walked per week, number of strength exercise days per week, and the presence of chronic diseases (hypertension, type 2 diabetes, hypercholesterolemia, and hypertriglyceridemia).

Spouse cohabitation was defined as living with a spouse. The weekly walking days were classified into four groups: no walking at all, 1-3 days walking, 4-6 days walking, and daily walking. The weekly strength exercise days were divided into three groups: no exercise at all, 1-3 days, and 4 or more days.

\section{Sleep Habits and Subjective Health Perception}

We defined sleep duration in this study as the difference between sleeping time and waking time and classified into five groups: under 6 hours, 6-7 hours, 7-8 hours, 8-9 hours, and more than 9 hours. Sleeping time was classified into six groups: before $9 \mathrm{pm}$, 9-10 pm, 10-11 pm, 11-12 pm, 12-1 am, and after $1 \mathrm{am}$. Waking up time was classified into six stages: before $4 \mathrm{am}, 4-5 \mathrm{am}, 5-6 \mathrm{am}$, 6-7 am, 7-8 am, and after $8 \mathrm{am}$. Subjective health perception was classified into three stages: good, normal, and bad. Health perception data were acquired from responses to a simple question ("how do you normally think of your health?").

\section{Statistical Analysis}

We performed statistical analysis using complex sample analysis in IBM SPSS Statistics for Windows, version 23.0 (IBM, Armonk, NY, USA). We used t-tests to compare the mean age and weekday and weekend sleeping times among the participants. We used chisquare tests to compare the age groups, spouse living status, household income, hypertension, diabetes mellitus, hypercholesterolemia, hypertriglyceridemia, weekly walking days, weekly strength exercise days, and subjective health status between older men and women.

We also used chi-square tests to compare the differences in weekday and weekend sleep duration, sleeping time, and waking up time between older men and women. We applied a generalized linear model to compare differences in sleep duration according to sleeping and waking times on weekdays and weekends between older men and women. Ordinal regression was used to examine the relationship between subjective health and stages of sleep duration, sleeping time, and waking time.

\section{Results}

\section{Baseline Participants Characteristics}

The mean ages of the men and women in this study were 72.26 \pm 0.239 and $74.41 \pm 0.203$ years, respectively. The age composition differed significantly by sex $(\mathrm{p}<0.01)$. We also observed a difference in the spouse cohabitation status between men and women $(\mathrm{p}<0.01)$. The sleep duration was longer in men compared to that in women on both weekdays and weekends. The prevalence of hypertension, diabetes mellitus, and hypertriglyceridemia did not differ significantly between men and women; however, the prevalence of hypercholesterolemia differed significantly $(\mathrm{p}<0.01)$. The walking days in a week did not differ significantly between the sex; however, muscular exercise duration and walking practice were significantly higher in men than in women (Table 1).

\section{Comparisons of Sleep Duration, Sleeping Time, and Waking Time between Men and Women}

Weekday and weekend sleep durations differed significantly between men and women $(\mathrm{p}<0.012)$. Sleep durations between 7 and 8 hours were highest on weekdays. The weekend sleep duration differed significantly between men and women $(p=0.006)$. On weekdays, the most common sleep time was between $10 \mathrm{pm}$ and $11 \mathrm{pm}$. The weekend sleeping times were similar to those on weekdays. There was no difference in sleeping time between the sexes with regard to weekend sleeping time. On weekdays, the 
Table 1. Baseline participant characteristics

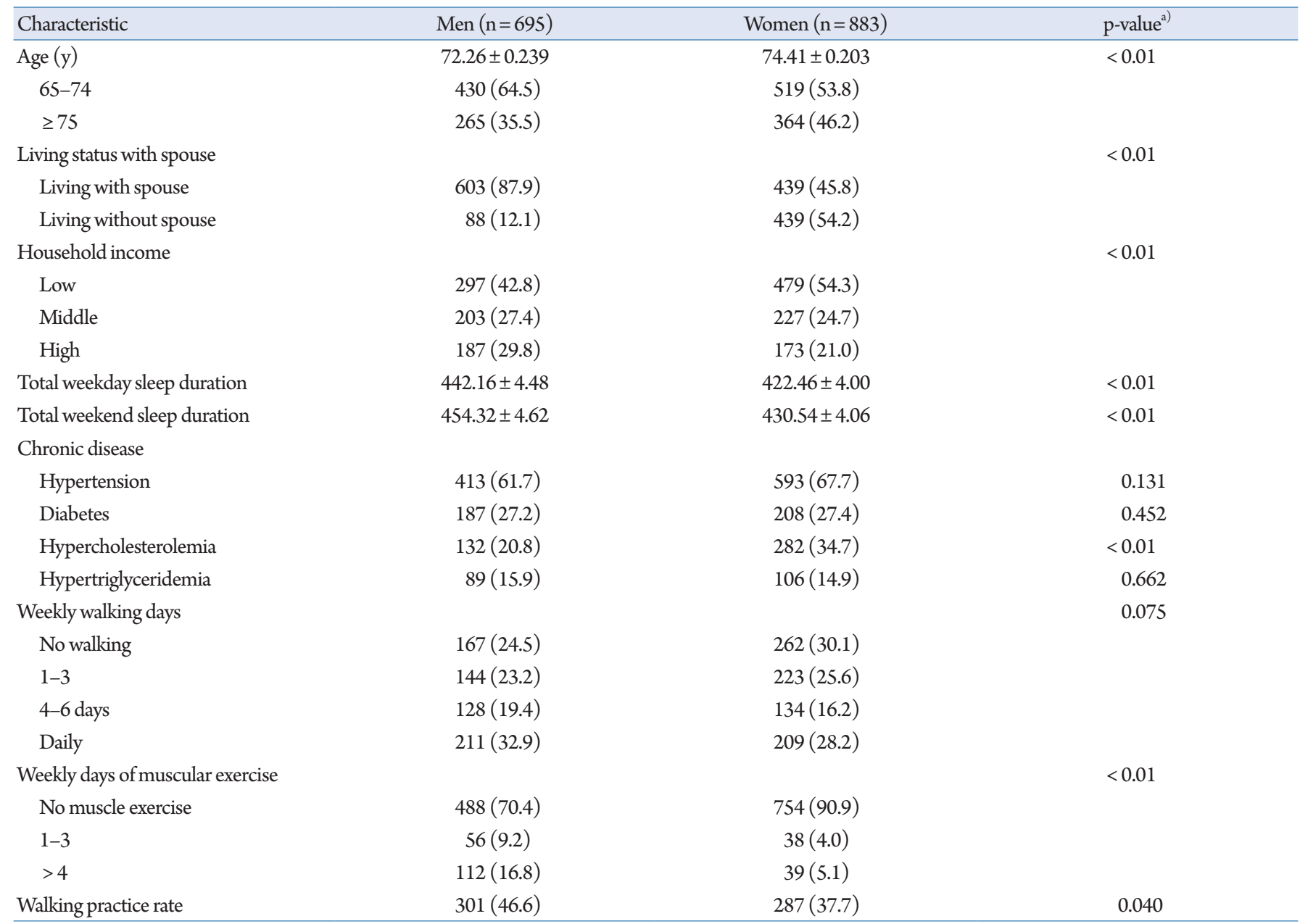

Values are presented as mean \pm standard error or number (\%).

a) t-test or chi-square test.

waking times for both were predominantly between 5 am and 6 am (Table 2).

\section{Sleep Duration according to Sleeping and Waking Times on Weekdays and Weekends}

The weekday sleep durations in men and women who went to sleep between 10 and $11 \mathrm{pm}$ were $447.56 \pm 5.13$ and $435.04 \pm 6.02 \mathrm{~min}-$ utes, respectively, and $454.22 \pm 5.78$ and $441.21 \pm 6.18$ minutes, respectively, on the weekends. The weekend sleep duration was higher than the weekday sleep duration. The sleep duration of men who woke between 6 and 7 am on weekdays did not differ from those who woke between 7 and 8 am and after 8 am (Table 3).

\section{Relationships between Sleep Habits and Subjective Health}

The weekday and weekend sleeping durations were associated with subjective health in men $(\mathrm{p}<0.05)$ but not in women. Compared to a sleep duration of 7 hours, a duration of 9 hours was sig- nificantly associated with improved health perception in men. Sleeping and waking times on weekdays and weekends were not related to subjective health in either sex (Table 4).

\section{Discussion}

This study investigated the associations between sleep habits and subjective health perception. A previous study reported that sleep duration affected the quality of life at all ages, as assessed by the European Quality of Life-5 Dimensions (EQ-5D) index. ${ }^{14)}$ Inconsistent with the results of our study, previous studies reported an association between the quality of life and sleep patterns. However, previous studies also reported that responses to the EQ-5D were related to subjective health status. ${ }^{15,16)}$ This trend was expected to be prominent in older adults who often have an overall lower quality of sleep. ${ }^{11)}$ We observed different associations between sleep habits and health perceptions between sexes in the present study. 
Table 2. Comparisons of sleep duration, sleeping time, and waking time between men and women

\begin{tabular}{|c|c|c|c|}
\hline Sleep habit & Male $(n=695)$ & Female $(\mathrm{n}=883)$ & $\mathrm{p}$-value $\mathrm{a}^{\mathrm{a}}$ \\
\hline Weekday sleep duration (hr) & & & 0.012 \\
\hline$<6$ & $73(13.0)$ & $148(18.3)$ & \\
\hline $6-7$ & $111(18.0)$ & $160(21.1)$ & \\
\hline $7-8$ & $186(26.0)$ & $223(26.6)$ & \\
\hline $8-9$ & $162(24.5)$ & $165(18.7)$ & \\
\hline$>9$ & $122(18.5)$ & $132(15.4)$ & \\
\hline Weekend sleep duration (hr) & & & 0.006 \\
\hline$<6$ & $69(12.1)$ & $140(17.0)$ & \\
\hline $6-7$ & $93(15.7)$ & $157(19.4)$ & \\
\hline $7-8$ & $179(24.6)$ & $210(25.9)$ & \\
\hline $8-9$ & $164(24.7)$ & $176(19.9)$ & \\
\hline$>9$ & $148(22.9)$ & $145(17.8)$ & \\
\hline Weekday sleeping time & & & 0.263 \\
\hline Before $9 \mathrm{pm}$ & $78(11.1)$ & $62(7.4)$ & \\
\hline $9 \mathrm{pm}-10 \mathrm{pm}$ & $156(21.5)$ & $192(21.4)$ & \\
\hline $10 \mathrm{pm}-11 \mathrm{pm}$ & $202(30.6)$ & $243(30.1)$ & \\
\hline $11 \mathrm{pm}-12 \mathrm{am}$ & $115(17.6)$ & $171(21.0)$ & \\
\hline $12 \mathrm{am}-1 \mathrm{am}$ & $72(13.0)$ & $107(13.8)$ & \\
\hline After $1 \mathrm{am}$ & $32(6.2)$ & $55(6.5)$ & \\
\hline Weekend sleeping time & & & 0.066 \\
\hline Before $9 \mathrm{pm}$ & $79(11.4)$ & $59(7.2)$ & \\
\hline $9 \mathrm{pm}-10 \mathrm{pm}$ & $150(21.6)$ & $171(18.8)$ & \\
\hline $10 \mathrm{pm}-11 \mathrm{pm}$ & $199(29.3)$ & $241(29.7)$ & \\
\hline $11 \mathrm{pm}-12 \mathrm{am}$ & $119(18.2)$ & $176(21.8)$ & \\
\hline $12 \mathrm{am}-1 \mathrm{am}$ & $78(13.8)$ & $123(15.1)$ & \\
\hline After 1 am & $29(5.6)$ & $59(7.3)$ & \\
\hline Weekday waking time & & & 0.250 \\
\hline Before 4 am & $33(5.5)$ & $61(7.7)$ & \\
\hline $4 \mathrm{am}-5 \mathrm{am}$ & $100(13.8)$ & $140(16.7)$ & \\
\hline $5 \mathrm{am}-6 \mathrm{am}$ & $205(30.3)$ & $244(30.5)$ & \\
\hline $6 \mathrm{am}-7 \mathrm{am}$ & $186(28.5)$ & $227(25.9)$ & \\
\hline $7 \mathrm{am}-8 \mathrm{am}$ & $94(14.8)$ & $113(13.7)$ & \\
\hline After 8 am & $37(7.4)$ & $47(5.5)$ & \\
\hline Weekend waking time & & & 0.395 \\
\hline Before 4 am & $32(5.4)$ & $55(6.9)$ & \\
\hline $4 a m-5 a m$ & $78(10.7)$ & $122(14.3)$ & \\
\hline 5 am-6 am & $200(29.8)$ & $221(27.4)$ & \\
\hline $6 \mathrm{am}-7 \mathrm{am}$ & $178(26.6)$ & $231(26.2)$ & \\
\hline $7 \mathrm{am}-8 \mathrm{am}$ & $109(16.8)$ & $128(15.2)$ & \\
\hline After 8 am & $57(10.8)$ & $75(10.1)$ & \\
\hline
\end{tabular}

Values are presented as number (\%).

${ }^{\text {a) }}$ Chi-square tests.

In this study, weekday and weekend sleep durations were associated with subjective health perception in men but not in women. Subjective health perception is how an individual perceives his or her health, which may differ from their actual health. However, negative subjective health perceptions are associated with an in- creased prevalence of depression or stress-related symptoms; ${ }^{17,18)}$ thus, subjective health perception is considered an objective indicator of health. ${ }^{19)}$ In this study, men with sleep durations of 9 hours perceived their subjective health to be significantly compared that in men with 7 hours of sleep duration on both weekdays and week- 
Table 3. Sleep duration according to sleeping and waking time of weekdays and weekends

\begin{tabular}{|c|c|c|c|c|c|c|}
\hline \multirow{2}{*}{ Sleep pattern } & \multicolumn{3}{|c|}{ Male $(n=695)$} & \multicolumn{3}{|c|}{ Female $(n=883)$} \\
\hline & Estimate & SE & p-value ${ }^{a)}$ & Estimate & SE & p-value ${ }^{a}$ \\
\hline \multicolumn{7}{|c|}{ Weekday sleep duration by sleeping time } \\
\hline (Intercept) & 447.563 & 5.129 & $<0.001$ & 435.041 & 6.024 & $<0.001$ \\
\hline Before $9 \mathrm{pm}$ & 101.796 & 12.086 & $<0.001$ & 101.713 & 18.356 & $<0.001$ \\
\hline $9 \mathrm{pm}-10 \mathrm{pm}$ & 37.608 & 9.168 & $<0.001$ & 34.373 & 10.278 & 0.001 \\
\hline $11 \mathrm{pm}-12 \mathrm{am}$ & -36.835 & 9.375 & $<0.001$ & -35.172 & 9.758 & $<0.001$ \\
\hline $12 \mathrm{am}-1 \mathrm{am}$ & -74.05 & 11.888 & $<0.001$ & -79.515 & 9.543 & $<0.001$ \\
\hline After $1 \mathrm{am}$ & -140.895 & 18.051 & $<0.001$ & -141.493 & 17.881 & $<0.001$ \\
\hline $10 \mathrm{pm}-11 \mathrm{pm}$ & $0.000^{\mathrm{b})}$ & - & - & $0.000^{\mathrm{b})}$ & - & - \\
\hline \multicolumn{7}{|c|}{ Weekend sleep duration by sleeping time } \\
\hline (Intercept) & 454.215 & 5.763 & $<0.001$ & 441.421 & 6.132 & $<0.001$ \\
\hline Before $9 \mathrm{pm}$ & 102.563 & 12.114 & $<0.001$ & 98.29 & 21.28 & $<0.001$ \\
\hline $9 \mathrm{pm}-10 \mathrm{pm}$ & 47.493 & 11.645 & $<0.001$ & 43.685 & 9.496 & $<0.001$ \\
\hline $11 \mathrm{pm}-12 \mathrm{am}$ & -28.158 & 9.95 & 0.005 & -24.546 & 8.972 & $<0.001$ \\
\hline $12 \mathrm{am}-1 \mathrm{am}$ & -67.624 & 10.681 & $<0.001$ & -70.313 & 10.314 & $<0.001$ \\
\hline After $1 \mathrm{am}$ & -131.391 & 19.439 & $<0.001$ & -139.416 & 17.031 & $<0.001$ \\
\hline $10 \mathrm{pm}-11 \mathrm{pm}$ & $0.000^{\mathrm{b})}$ & - & - & $0.000^{\mathrm{b})}$ & - & - \\
\hline \multicolumn{7}{|c|}{ Weekday sleep duration by wake time } \\
\hline (Intercept) & 471.848 & 7.352 & $<0.001$ & 447.212 & 6.454 & $<0.001$ \\
\hline Before 4 am & -130.92 & 17.645 & $<0.001$ & -138.742 & 13.421 & $<0.001$ \\
\hline $4 \mathrm{am}-5 \mathrm{am}$ & -92.516 & 11.759 & $<0.001$ & -75.769 & 10.7 & $<0.001$ \\
\hline $5 \mathrm{am}-6 \mathrm{am}$ & -47.398 & 9.588 & $<0.001$ & -39.449 & 8.521 & $<0.001$ \\
\hline $7 \mathrm{am}-8 \mathrm{am}$ & 19.492 & 10.114 & 0.054 & 46.299 & 11.558 & $<0.001$ \\
\hline After 8 am & 23.22 & 21.718 & 0.285 & 78.164 & 21.072 & $<0.001$ \\
\hline $6 \mathrm{am}-7 \mathrm{am}$ & $0.000^{\mathrm{b})}$ & - & - & $0.000^{\mathrm{b})}$ & - & - \\
\hline \multicolumn{7}{|c|}{ Weekend sleep duration by wake time } \\
\hline (Intercept) & 474.45 & 7.28 & $<0.001$ & 442.249 & 5.562 & $<0.001$ \\
\hline Before 4 am & -123.436 & 17.311 & $<0.001$ & -128.5 & 14.004 & $<0.001$ \\
\hline $4 a m-5 a m$ & -87.397 & 12.844 & $<0.001$ & -71.917 & 10.068 & $<0.001$ \\
\hline $5 \mathrm{am}-6 \mathrm{am}$ & -49.029 & 9.544 & $<0.001$ & -36.231 & 7.982 & $<0.001$ \\
\hline $7 \mathrm{am}-8 \mathrm{am}$ & 21.684 & 9.699 & 0.026 & 49.862 & 10.466 & $<0.001$ \\
\hline After 8 am & 62.479 & 19.179 & 0.001 & 98.845 & 15.104 & $<0.001$ \\
\hline $6 \mathrm{am}-7 \mathrm{am}$ & $0.000^{\mathrm{b})}$ & - & - & $0.000^{\mathrm{b})}$ & - & - \\
\hline
\end{tabular}

SE, standard error.

${ }^{\text {a) }}$ Analysis of variance.

${ }^{b)}$ Reference (standard time).

ends. However, compared to 7 hours of sleep duration, we observed no significant difference in subjective health perception for other sleep durations. Older adults have a higher prevalence of sleep disorders; ${ }^{10,11)}$ thus, the impact of insufficient sleep duration on subjective health perception could be greater in this population than in younger populations. In other words, if older adults perceive that they are lacking sleep, their subjective health perception is likely to be worse compared to those in younger populations.

Many factors affect positive subjective health perception; among these, a sleep duration that is not too long and not too short is important, ${ }^{5)}$ which is consistent with our results. However, subjective health perception was not related to sleeping or waking times in men in our study. Lifestyle determines sleeping or waking time, and these are considered insignificant if the sleep duration is sufficient.

In women, sleep duration, sleeping time, and waking time were not related to subjective health perception. The prevalence of sleep disorders is higher in older women than in older men. ${ }^{20,21)}$ Thus, sleep disorders may negatively affect the relationship between sleep habits and subjective health perception compared to that in individuals without sleep disorders. Therefore, sleep habits are unlikely to be a significant factor for subjective health perception in older women with sleep disorders. Also, sleep patterns of older women might be affected by both social and familial roles, meanwhile these in older men are more likely to be affected by only social roles, in Korean cultural perspective. Additionally, alterations 
Table 4. Relationships between sleep habits and subjective health

\begin{tabular}{|c|c|c|c|c|c|c|c|c|c|c|c|c|}
\hline & \multicolumn{6}{|c|}{ Male } & \multicolumn{6}{|c|}{ Female } \\
\hline & \multicolumn{3}{|c|}{ Weekday } & \multicolumn{3}{|c|}{ Weekend } & \multicolumn{3}{|c|}{ Weekday } & \multicolumn{3}{|c|}{ Weekend } \\
\hline & OR & $95 \% \mathrm{CI}$ & p-value ${ }^{\text {a) }}$ & OR & $95 \% \mathrm{CI}$ & p-value ${ }^{a)}$ & OR & $95 \% \mathrm{CI}$ & p-value $e^{a)}$ & OR & $95 \% \mathrm{CI}$ & p-value \\
\hline 5 & 1.053 & $0.496-1.819$ & & 1.076 & $0.572-2.024$ & & 1.559 & $0.912-2.668$ & & 1.371 & $0.811-2.319$ & \\
\hline 6 & 1.016 & $0.583-1.661$ & & 0.891 & $0.514-1.547$ & & 1.053 & $0.682-1.626$ & & 1.138 & $0.725-1.786$ & \\
\hline 8 & 0.966 & $0.664-1.613$ & & 0.983 & $0.622-1.553$ & & 1.186 & $0.807-1.743$ & & 1.076 & $0.727-1.593$ & \\
\hline 7 & 1 & - & & 1 & - & & 1 & - & & 1 & - & \\
\hline Sleeping time & & & 0.058 & & & 0.148 & & & 0.815 & & & 0.801 \\
\hline$<9 \mathrm{pm}$ & 0.495 & $0.250-0.982$ & & 0.621 & $0.313-1.231$ & & 1.015 & $0.547-1.883$ & & 0.947 & $0.543-1.651$ & \\
\hline $9 \mathrm{pm}-10 \mathrm{pm}$ & 0.787 & $0.531-1.164$ & & 0.876 & $0.580-1.325$ & & 0.897 & $0.608-1.325$ & & 0.835 & $0.575-1.212$ & \\
\hline $11 \mathrm{pm}-12 \mathrm{am}$ & 0.949 & $0.606-1.486$ & & 1.185 & $0.769-1.827$ & & 1.081 & $0.703-1.662$ & & 1.003 & $0.692-1.454$ & \\
\hline Waking time & & & 0.999 & & & 0.561 & & & 0.132 & & & 0.206 \\
\hline$<4 \mathrm{am}$ & 1.059 & $0.522-2.148$ & & 0.880 & 0.431-1.799 & & 0.939 & $0.462-1.907$ & & 0.886 & $0.473-1.589$ & \\
\hline $4 a m-5 a m$ & 0.981 & $0.608-1.584$ & & 0.856 & $0.515-1.423$ & & 1.296 & $0.767-2.192$ & & 1.237 & $0.772-1.982$ & \\
\hline $5 \mathrm{am}-6 \mathrm{am}$ & 1.027 & $0.668-1.580$ & & 1.283 & $0.823-2.000$ & & 1.492 & $0.998-2.229$ & & 1.303 & $0.906-1.873$ & \\
\hline $7 \mathrm{am}-8 \mathrm{am}$ & 0.960 & $0.581-1.588$ & & 1.208 & $0.700-2.086$ & & 0.874 & $0.545-1.403$ & & 0.829 & $0.515-1.334$ & \\
\hline$>8 \mathrm{am}$ & 0.906 & $0.495-1.660$ & & 0.847 & $0.405-1.770$ & & 1.084 & $0.614-1.913$ & & 0.750 & $0.378-1.488$ & \\
\hline $6 \mathrm{am}-7 \mathrm{am}$ & 1 & - & & 1 & - & & 1 & - & & 1 & - & \\
\hline
\end{tabular}

OR, odds ratio; $\mathrm{CI}$, confidence interval.

${ }^{\text {a) }}$ Ordinal regression.

in sleeping patterns may differ between older men and women. In older men, a lack of deep sleep is a major problem, while sleep latency was a predominant sleeping problem in older women. ${ }^{22}$ Consequently, insufficient sleep duration was related to poor subjective health perception in older men lacking deep sleep.

We observed associations between weekday and weekend sleep duration and subjective health perception in men. These results may inform the regulation of health policy in this population. Generally, 8 hours is considered a sufficient sleep duration in adults, although one study reported 7 hours to be sufficient. ${ }^{23)}$ Older men with a lack of deep sleep may not perceive their subjective health to be high despite having a sufficient sleep duration (7-8 hours); in this study, those with 9 hours of sleep duration perceived their health to be good. Subjective health perception is not a substitute for actual health status but is helpful as an objective indicator to predict the actual health status. ${ }^{24,25)}$ Additionally, one study reported that poor perception of subjective health increased the risk of suicide and decreased daily life activities. ${ }^{8,26)}$ Thus, older men may not sleep enough due to sleep disorders, or if they did sleep, their sleep duration was less than 8 hours. Their subjective perception could also be deteriorating, leading to an increased risk of disease.
Therefore, sleep duration should be assessed in the initial medical examinations of older men. If the sleep duration is insufficient, sleep hygiene should be managed or pharmacologic intervention should be considered. Further study is needed regarding the effects on older adult women.

This study has a few limitations. First, due to the cross-sectional design, the observed relationships established did not establish causality. Prospective studies are needed to clarify the causality of subjective health perception and sleep habits. Second, data on medical history and sleep patterns were obtained through a questionnaire; thus, missing variables or overstatement are possible. The question used to estimate sleep duration, "when do you usually go to bed and when do you wake up?" was very simple and might not reflect the average duration of sleep. Third, we analyzed only sleep habits as represented by sleep duration, sleeping time, and waking time, but not sleep quality, which was not considered is as important as sleep pattern. Despite these limitations, the strength of this study was that the study population may represent the Korean older population. Moreover, to our knowledge, this is the first study to assess the relationship between sleep habits and subjective health perception in this population. 
In conclusion, weekday and weekend sleep durations were related to subjective health perception in older men. Additional studies are needed to determine how sleep habits, including sleep quality, affect the subjective health perception of older adults.

\section{ACKNOWLEDGMENTS}

\section{CONFLICT OF INTEREST}

The researchers claim no conflicts of interest.

\section{FUNDING}

This work was supported by a 2-year research grant from Pusan National University.

\section{AUTHOR CONTRIBUTIONS}

Conceptualization, YJK; Data curation, YJK; Funding acquisition, YJK; Methodology, YJK; Supervision, YJK; Investigation, HRH; Writing original draft, HRH; Reviewing \& editing, HRH.

\section{REFERENCES}

1. Foley D, Ancoli-Israel S, Britz P, Walsh J. Sleep disturbances and chronic disease in older adults: results of the 2003 National Sleep Foundation Sleep in America Survey. J Psychosom Res 2004; 56:497-502.

2. Wallander MA, Johansson S, Ruigomez A, Garcia Rodriguez LA, Jones R. Morbidity associated with sleep disorders in primary care: a longitudinal cohort study. Prim Care Companion J Clin Psychiatry 2007;9:338-45.

3. Lee M, Choh AC, Demerath EW, Knutson KL, Duren DL, Sherwood RJ, et al. Sleep disturbance in relation to health-related quality of life in adults: the Fels Longitudinal Study. J Nutr Health Aging 2009; 13:576-83.

4. Silva GE, An MW, Goodwin JL, Shahar E, Redline S, Resnick H, et al. Longitudinal evaluation of sleep-disordered breathing and sleep symptoms with change in quality of life: the Sleep Heart Health Study (SHHS). Sleep 2009;32:1049-57.

5. Magee CA, Caputi P, Iverson DC. Relationships between self-rated health, quality of life and sleep duration in middle aged and elderly Australians. Sleep Med 2011;12:346-50.

6. Tel $\mathrm{H}$. Sleep quality and quality of life among the elderly people. Neurol Psychiatry Brain Res 2013;19:48-52.

7. Lewis LM, Riegel BJ. Determinants of perceived health in older adults with hypertension. Heart Lung 2010;39:41-9.

8. Menec VH. The relation between everyday activities and successful aging: a 6-year longitudinal study. J Gerontol B Psychol Sci Soc Sci 2003;58:S74-82.
9. Li J, Vitiello MV, Gooneratne NS. Sleep in normal aging. Sleep Med Clin 2018;13:1-11.

10. Rodriguez JC, Dzierzewski JM, Alessi CA. Sleep problems in the elderly. Med Clin North Am 2015;99:431-9.

11. Amer MS, Hamza SA, El Akkad RM, Abdel Galeel YI. Does self-reported sleep quality predict poor cognitive performance among elderly living in elderly homes? Aging Ment Health 2013;17:788-92.

12. Korea Institute of Health and Social Affairs. Korea National Health and Nutrition Examination Survey 2017 [Internet]. Sejong, Korea: Ministry of Health and Welfare; c2019 [cited 2020 Jun 1]. Available from: https://knhanes.cdc.go.kr/knhanes/ sub04/sub04_03.do?classType $=7$.

13. Korean Ministry of Health and Welfare. The 7th Korea National Health and Nutrition Examination Survey (KNHANES VII-1). Sejong, Korea: Ministry of Health and Welfare; 2016.

14. Cho J, Kwak N, Choi SM, Lee J, Park YS, Lee CH, et al. Sleep duration and health-related quality of life in Korean adults: 2007 2015 Korea National Health and Nutrition Examination Survey. Sleep Breath 2019;Dec 2;[Epub]. http://doi.org/10.1007/ s11325-019-01972-7.

15. Golicki D, Niewada M, Jakubczyk M, Wrona W, Hermanowski T. Self-assessed health status in Poland: EQ-5D findings from the Polish valuation study. Pol Arch Med Wewn 2010;120:27681.

16. Konig HH, Bernert S, Angermeyer MC, Matschinger H, Martinez M, Vilagut G, et al. Comparison of population health status in six European countries: results of a representative survey using the EQ-5D questionnaire. Med Care 2009;47:255-61.

17. Park JI, Park TW, Yang JC, Chung SK. Factors associated with depression among elderly Koreans: the role of chronic illness, subjective health status, and cognitive impairment. Psychogeriatrics 2016;16:62-9.

18. Bailis DS, Segall A, Mahon MJ, Chipperfield JG, Dunn EM. Perceived control in relation to socioeconomic and behavioral resources for health. Soc Sci Med 2001;52:1661-76.

19. Gold M, Franks P, Erickson P. Assessing the health of the nation: the predictive validity of a preference-based measure and self-rated health. Med Care 1996;34:163-77.

20. Brabbins CJ, Dewey ME, Copeland JR, Davidson IA, McWilliam C, Saunders P, et al. Insomnia in the elderly: prevalence, gender differences and relationships with morbidity and mortality. Int J Geriatr Psychiatry 1993;8:473-80.

21. Arber S. Gender, marital status and sleep problems in Britain. Przegl Lek 2012;69:54-60.

22. Luca G, Haba Rubio J, Andries D, Tobback N, Vollenweider P, Waeber G, et al. Age and gender variations of sleep in subjects 
without sleep disorders. Ann Med 2015;47:482-91.

23. Taheri S, Lin L, Austin D, Young T, Mignot E. Short sleep duration is associated with reduced leptin, elevated ghrelin, and increased body mass index. PLoS Med 2004;1:e62.

24. Cockerham WC, Sharp K, Wilcox JA. Aging and perceived health status.J Gerontol 1983;38:349-55.
25. Luchi CA, Peres KG, Bastos JL, Peres MA. Inequalities in self-rated oral health in adults. Rev Saude Publica 2013;47:740-51.

26. Fujino Y, Mizoue T, Tokui N, Yoshimura T. Prospective cohort study of stress, life satisfaction, self-rated health, insomnia, and suicide death in Japan. Suicide Life Threat Behav 2005;35:22737. 